\title{
Implementing Feminist Language Pedagogy: Development of Students' Critical Consciousness and L2 Writing
}

\author{
Hayley Anne Cannizzo
}

Citation: Cannizzo, H.A.

Implementing Feminist Language

Pedagogy: Development of Students'

Critical Consciousness and L2

Writing. Educ. Sci. 2021, 11, 393.

https://doi.org/10.3390/

educsci11080393

Academic Editor: Maureen Kendrick

Received: 31 March 2021

Accepted: 15 July 2021

Published: 2 August 2021

Publisher's Note: MDPI stays neutral with regard to jurisdictional claims in published maps and institutional affiliations.

Copyright: (C) 2021 by the author. Licensee MDPI, Basel, Switzerland. This article is an open access article distributed under the terms and conditions of the Creative Commons Attribution (CC BY) license (https:// creativecommons.org/licenses/by/ $4.0 /)$.
Department of Second Language Studies, University of Hawaii at Manoa, Honolulu, HI 96813, USA; cannizzo@hawaii.edu

\begin{abstract}
Feminist pedagogy is a teaching practice, philosophy and process that seeks to confront and deconstruct oppressive power structures both within and outside of the classroom using a gendered lens. As Women's Studies departments continue to grow in many universities, feminist pedagogy seems to be gaining popularity as an approach to engaging students in liberatory classroom practices. However, feminist language pedagogy (feminist pedagogy in the second language learning context) appears to have stagnated. This paper investigates the implementation of feminist language pedagogy in an EAP writing classroom for first-year students at a public university in the Southwest of the United States. Using action research, the teacher, who is the author of this paper, examined how feminist language pedagogy aids the development of her students' critical consciousness and serves as a motivational tool for L2 writing development. The author finds that even in a short, sixteen-week semester, it is possible for students to foster critical consciousness without sacrificing linguistic development.
\end{abstract}

Keywords: feminist language pedagogy; feminist pedagogy; critical pedagogy; critical language teaching; feminist classroom practices; critical consciousness; L2 writing

\section{Introduction}

Feminism, like antiracism, is thus not simply one more social issue in ESL but a way of thinking, a way of teaching, and, most importantly, a way of learning.

-Arleen Schenke, 1996, p. 158

In light of current social movements such as Black Lives Matter and Me Too that bring intersectional issues around power and identity to the forefront of our consciousness, educational discourse continues to discuss the need for more critically engaged, active citizens. It seems then that it is almost evident-if not necessary-for educators to explore feminist pedagogy (FP) and have conversations about how to implement it in their classrooms. As Arleen Schenke rightly states in the above epigraph, FP is not just "another social issue" and does not simply mean discussing gender issues with students. Feminist pedagogy, as Schniedewind [1] illustrated, is a process by which both students and teachers engage in confronting and deconstructing oppressive power structures. It is a way of thinking, learning, teaching and interacting with the divisive world in which we reside.

While there is evidence of FP being used successfully in mainstream education, recently, it has been largely left out of second language learning contexts. As such, this paper explores how I implemented feminist language pedagogy (FLP) at a flagship US university in my English for Academic Purposes (EAP) classroom. Using action research, I assumed the role of a teacher-researcher and explored the effects FLP had on my fourteen ELL (English language learners) students' thinking and L2 writing development. Ultimately, I argue that FLP can be used as a consciousness-raising tool that benefits students' critical consciousness and second language development and urge educators to explore feminist classroom practices. 


\section{Feminist Pedagogy}

\subsection{Background}

Feminist pedagogy's historical genealogy has been traced back to the political climate of the US women's movement in the 1960s [2,3]. During this time women's consciousnessraising groups began to form. In these groups, "activist[s] and politically committed women came to apply the universal demands for equality and justice of the [US] civil rights movement to their own situation as women" ([3], p. 456). Certain tenets that developed out of the radical nature of feminist consciousness-raising groups have become an essential foundation upon which feminist pedagogy is grounded. This includes "certain assumptions about knowledge, power, and political action" ([3], p. 456).

According to Weiler, fundamental to early consciousness-raising groups were their call and desire for political action. Groups desired and sought radical change that got to the root of societal problems. Another fundamental tenet was centering emotion and lived experience as sites of knowledge and power. Consciousness-raising groups challenged the Eurocentric framing of emotion and lived experience as untrustworthy and irrational and scientific knowledge as testable, rational truth [4]. Lastly, consciousness-raising groups relied on assumptions of commonality amongst women and women's struggles. This last aspect has been heavily critiqued by Black, queer and Indigenous feminists, such as bell hooks, Audre Lorde, Patricia Hill Collins, Gloria Anzaldùa, Haunani Kay-Trask and Angela Davis among others, who point to the US, Western feminism's centering of mostly white, middle class, cis-women's experiences as universal. They point to the erasure of important differences and a "failure to acknowledge both the intersections of race, class, gender, and sexuality and the historic dispensations of whiteness" ([5], p. 330).

As the women's movement continued to grow and expand in the Western world, so did feminist theory, practice and pedagogy. Modern day feminism is still infused with tenets that came from consciousness-raising groups such as a desire for political action and recognizing emotion and lived experience as knowledge. However, it has also taken up Black, Indigenous and queer feminist critique, recognizing that there is no universal female experience. It uses intersectionality-a term originally coined by Kimberlé Crenshaw in 1989 - as an analytical framework to conceptualize the relationships among and between systems of oppression by examining how a person's overlapping identities (such as race, class, age, ability, gender, sex, etc.) are made relevant in certain contexts and interact to create different manners of discrimination, oppression and privilege. As such, feminism has evolved into an intersectional field of activism, study and politics that critiques not only patriarchy but also colonialism, racism, white supremacy, neoliberalism and capitalism amongst other things [6].

Like other social justice-oriented pedagogies, such as critical pedagogy, FP seeks to "support the development of active, engaged citizens" by interrogating oppressive power structures and empowering students to become agents for positive change [2] (p. 8). FP shares similar goals with other liberatory pedagogies-such as creating liberatory, democratic classrooms that critically analyze oppressive systems-and methodologiessuch as decentering the teacher to disrupt classroom power structures, negotiating course content, and using dialogical practices to pose questions about society. At the same time, FP differs from other liberatory pedagogies in that its foundation and analytical lens is gender. Having evolved alongside feminist theory and politics, FP takes up current feminist ideas. It focuses on the intersection of gender, race, class, age and ability and rejects universal and dualistic claims of the oppressor and the oppressed by exploring how identity is enacted through and entwined with oppressive and discriminatory systems of power [3]. It interrogates all points and angles of privilege, power relations and hierarchies. FP considers questions of subjectivity and meaning making and explores the complex, intersectional workings of oppression-acknowledging that, depending on the context, environment and structures at work, those who are oppressed may also act as oppressors [3]. Ochoa and Pershing [7] provide a definition of feminist pedagogy that I find useful and which pays tribute to the emphasis it places on intersectional thinking. They state: 
Feminist pedagogy examines power dynamics both inside and outside the classroom. It encourages learners to focus on their own and others' lived realities and experiences through a lens that examines gender, race, class, sexual identity, and other categories of power and marginalization. It acknowledges oppressed people and does not separate knowledge from the sociocultural contexts in which it is produced.

—Ochoa and Pershing, 2011, p. 26

\subsection{Tenets of Feminist Pedagogy}

Since FP uses gender as a gateway to critically examine oppressive systems, the content of feminist classrooms often evokes gender and social issues. However, FP is not solely concerned with course content, but also with teaching practices that show students how to engage in a feminist classroom. This is what Schniedewind [1] refers to as the feminist process. Schniedewind argues that an important element of FP is teaching feminist process skills: “ . . the classroom process skills that embody feminist principles [are] (1) communicating (2) developing a democratic group process (3) cooperating (4) integrating theory and practice, and (5) networking and organizing" ([1], p. 17). Schniedewind's hope is that by engaging in feminist process skills and teaching practices, feminist teachers can create an environment where students learn how to participate in a feminist classroom, that is, where power is shared, personal experiences and emotions are valued, a feminist consciousness prevails and students work for change.

Another major goal of FP is to interrogate oppression and advocate for justice through action. One way it seeks to do so is by raising students' critical and feminist consciousness. When referencing critical consciousness (CC), let us turn to Lundy's [8] definition as "both reflection on and an understanding of dehumanizing social structures [that] includes action directed at changing societal conditions" (p. 172). Similarly, Klatch [9] defines feminist consciousness as "[requiring] the recognition and rejection of unequal and unfair treatment of women and the transformation from seeing problems as personal to perceiving the social nature of problems that require political solutions" (p. 792). Here, it is important to note that modern day feminist theory recognizes and privileges difference; that is to say, feminist consciousness does not emphasize any understanding of universal roles of "women" or "female" but, as Reimer [10] points out, "looks at the culturally specific ways in which [these roles are] performed and valued" (p. 79). Both critical and feminist consciousness emphasize the recognition and reflection on social processes and structures as sites and producers of oppression. Both also share a common goal of directing action towards challenging and changing these processes and structures. Feminist consciousness, then, may be seen as a category or domain of critical consciousness that uses a gendered lens to recognize and reflect on oppressive systems of power. By using teaching practices aimed at raising students' CC, feminist educators hope students will identify the ways in which power and oppression work in their own and other's lives and subsequently take action towards combating inequality.

Another key element of the feminist classroom is that it seeks to validate students' selfknowledge by encouraging them to pull from their own lived experiences and emotions as a resource. In doing so, students and teachers simultaneously learn from each other by engaging with and honoring multiple lived realities [7,11,12]. As hooks [11] explains, validating and centering students" experiences engages them "in a learning process that makes the world 'more rather than less real'" (p. 49). Boler [13] also argues that bringing emotion and personal experience into the classroom is essential as emotions are often used as sites of oppression and control. She asserts that in a patriarchal society, we learn emotional rules that are used to maintain the status quo and hierarchies of race, class and gender. Boler reminds us that education not only informs our values and beliefs, but schools also function in the interest of the nation state. In other words, they work to maintain the social status quo. Thus, by legitimizing emotion and lived experience in the classroom, FP subverts the very patriarchal structures and rules that work to oppress it. 


\section{Feminist Language Pedagogy in Practice}

By interrogating power relations, raising students' critical consciousness and validating emotions, FP seeks to engage students in the knowledge and skills needed to become active citizens (i.e., students become active agents of change in and outside of the classroom) [1]. Many recent works have found success in FP. Most of these works have taken place in Women's Studies courses or departments, often at the secondary or university level; i.e., [14-17]. However, one place where FP seems to be particularly absent is in second language classrooms. While there has been much literature on the role of gender and gendered language [18-21] as well as how gender mediates second language acquisition in bilingual and multilingual environments [22-25], there is significantly less work on feminist pedagogical approaches in second language learning contexts (i.e., FLP). In fact, Vandrick [26-28] has been urging language educators for almost two decades to incorporate more feminist pedagogies into their classrooms. While there may not be many, there are some studies which illustrate what FP looks like in second language learning contexts [3,29-31].

One of the earliest studies that reports using FLP is Petrie's [30] ESL class in Canada. The course was for female learners who were returning to the classroom after years of being out of academic study and was offered through the Women's College. The material used was female-centered and power was shared with the students who chose the course topics. Much of the material focused on gender stereotypes, and Petrie recounts how this often caused heated discussion in which women would recount their personal stories and feelings. In addition to activities that included debates, interviews and discussions, every class had some focus on grammar, vocabulary and pronunciation. Petrie's class provides a good example of the possibility of implementing key feminist tenets into a classroom that also focuses on language learning and development.

A theme that seems to run throughout studies in which FP is used in the language classroom is that the classes are always "women-centered," meaning that material was focused on women, for women and about women. This follows Vandrick's [26] suggestion that an important aspect of applying FP in the second language classroom is to assign readings about gender issues, cite women as authorities as often as possible, look at cultural differences regarding gender, let students know about Women's Studies programs and be a role model of women or men that are supportive of gender equality. By creating a women-centered classroom and women-centered materials, the importance of women is made clear and it becomes easier for students to engage in discussion and activities about gender while imagining alternative realities $[26,27,29,30,32]$. One example of this can be seen in Schenke's [32] classroom, where she taught advanced ESL writing in Canada for a class of women. In the class, students discussed the portrayal of women in various soap operas. After discussions and readings that examined how women were represented in the shows, students wrote papers that linked their personal experiences and histories to their analysis of the soap operas. This led to students questioning and imagining what a feminist soap opera may look like, allowing them to envision new realities for the women in the shows and for themselves.

Though not as common as in ESL settings, FLP can occasionally be found in EFL settings [29,33,34]. McMahill [29] describes a phenomenon in Japan where "since the 1970s Japan-born women have been taking feminist pedagogy into their own hands by forming countless study and discussion groups," which she terms as "grassroots feminist English classes" (p. 308). In these courses, students organize the classes themselves, negotiate the content and decide who to hire as an instructor. The courses are virtually all female, usually run privately and not for profit. McMahill explains that the goal of the class is to combine the linguistic goal of improving English with feminist goals. She asserts that in the classroom, English is used not to imitate white, middle-class women's ways of speaking, but rather "As a weapon for self-empowerment as women in Japan and as women of color in the world" (p. 332). More recently, Cheira [35] described her use of FLP in an EFL context-a high school class in Portugal. In her class, Cheira used FLP to challenge 
gender stereotypes and dating violence among teenagers. Through the use of wonder tales that questioned and disrupted stereotypical gender roles, Cheira's students-like McMahill's-became self-empowered and started to resist stereotypes.

One of the most recent examples of FLP comes from Yoshihara's 2017 book [36] that examines the identity formation and teaching practices of eight feminist EFL teachers at a Japanese university. Using a poststructuralist lens, Yoshihara provides an in-depth look at the complex nature of modern feminist classrooms. She identifies certain values and practices that the feminist educators shared, such as valuing the importance of students' voice, emotions and experiences, rejecting teacher-centered approaches, challenging unequal power structures, advocating for gender equality, encouraging students to learn and think about injustice and both empowering and being empowered by students.

The above examples illustrate both the possibility of using FP in language learning contexts and the success it may have. However, examples of this kind are scarce and it appears that the use of FP in second language classrooms has stalled. New books and articles recounting success stories from feminist classrooms in mainstream education have come out as recently as the last two years $[37,38]$. However, the only recent publications known to the author that show FP being used in a second language learning context are Cheira's [35] above-noted article and Yoshihara's 2017 book [36]. The present study seeks to fill this gap by examining the implementation of FLP in the author's own English for Academic Purposes (EAP) classroom. Furthermore, few studies examine how the implementation of FLP may affect not only student's thinking, but also their language development. For this reason, the current paper examines how FLP can act as a tool for both motivating second language development and consciousness raising.

\section{Participants and Setting}

Fourteen ELLs participated in the present study. The students were 17-19 years of age at the time of the study and were all enrolled as first-year undergraduate students at a flagship American university. All the students in the class were multilingual and had advanced knowledge of the English language. At the time of the study, the students reported having lived in the US for varied amounts of time (ranging from 4 months to 5 years). The students had diverse backgrounds and represented nine different nationalities. Table 1 illustrates the countries of origin, number of students from each country and the students' corresponding L1s.

Table 1. Student Background Information.

\begin{tabular}{ccc}
\hline Students' Country of Origin & $\begin{array}{c}\text { Number of Students from } \\
\text { Each Country }\end{array}$ & Students' L1 \\
\hline China & 3 & Cantonese, Mandarin \\
\hline Czech Republic & 1 & Czech \\
\hline Egypt & 1 & Arabic \\
\hline Germany & 1 & German \\
\hline Japan & 2 & Japanese \\
\hline Korea & 2 & Korean \\
\hline Netherlands & 1 & Dutch \\
\hline Portugal & 1 & Portuguese \\
\hline Taiwan & 2 & Taiwanese, Mandarin \\
\hline
\end{tabular}

The class was a Foundations of Composition course that is a general education requirement for all undergraduate students at the university. The section of the course I taught was composed of and intended for students who have English as a second or additional language. Some of the students in the course did not identify as ELLs but as bilingual and 
resented being placed in an "ESL" course by the administration due to their test scores being below an established standard. Nevertheless, the goal of the class was to aid students in producing college-level academic writing. The class met twice a week for an hour and fifteen minutes per meeting during the sixteen-week term.

I was the instructor of the course and designed the curriculum and materials used throughout the semester. I intentionally planned the course to be an FLP class. Specifically, as a teacher-researcher, my aims were twofold: first, for my students to meet the mandated learning outcomes and succeed in producing college-level academic writing; second, I aimed to document, observe and assess to what extent it was possible to engage ELL students in an FLP curriculum and what the results of their engagement would be. Before enrolling, it was likely the students were aware the class was a Composition course with the aim of improving their college-level writing. However, they would not have been aware that the class was intentionally an FLP course. I felt it was important that my students were aware of this. Following hooks' [11] advice that feminist teachers should explain to students what to expect in a feminist classroom, I gave students a handout describing what FLP is during the first week of class. Together, we discussed the handout, and I explained that our class theme for the semester and for major assignments would be culture and gender. Additionally, at the start of week three, I explained to my students that I wanted to research our class and my FLP teaching. We discussed what this meant and I gave students a consent form to turn in during the next class so that they would have time to decide if they wanted to participate.

I divided the course into four units: Unit 1-introduction, unit 2-narrative writing, unit 3-argumentative research writing, unit 4-critical analysis writing. At the end of units 2-4, the students produced an essay over the unit focus (e.g., unit 2-narrative writing $=$ narrative essay). In addition to the major essay assignments, the students also completed smaller assignments throughout the semester such as weekly student-led free writes, outlines and other in-class activities.

In each major essay assignment, the students had to draw upon the course theme, "gender and culture." Additionally, I incorporated smaller assignments over the theme such as readings, reflections and worksheets. There were some days when the classroom content may not have appeared feminist at all and general writing skills were taught (for example, a lesson on in-text and parenthetical citations). However, I believe that for a classroom to be considered feminist, it does not need to discuss issues of gender daily but as often and as much as possible while still being consistent with and achieving other mandated student learning outcomes. I adhered to Schniedewind's [1] feminist process and focused on making not just the content, but my teaching practices feminist. I worked every day to integrate feminist process skills into my classroom and used teaching methods also found in other liberatory pedagogies such as grade negotiation, syllabus negotiation, fostering open dialogue and critical discussion, constructing a safe environment and trying as much as possible to shift power to students. In doing so, while there were days when the content may not have seemed feminist, I argue that myself and my students were working within a feminist classroom environment that was both negotiated and co-constructed.

Lastly on this point, it would be misleading to believe that a present-day feminist classroom deals exclusively with questions and issues surrounding gender. Following feminist theory, I worked to make my course as intersectional as possible. For example, the students led in-class free writes where they chose a social issue, presented it to the class and created guiding questions for their classmates to write about. Some examples of the issues the students chose were global warming, cyberbullying, gun control and homeschooling. This gave the students the opportunity to present and discuss critical issues that they found important and relevant to their lives. After the students finished their presentation, I always reframed the topic, examining it through a gendered lens, and sparked discussion on, for example, the ways cyberbullying or global warming might intersect with gender. Incorporating as many critical and intersectional topics as possible and always bringing it back to a gendered lens not only gave students freedom and choice, 
but also allowed those who did not initially see gender as interesting or relevant to their lives make new connections while discussing issues they found interesting. In other words, it not only made the class more feminist, but also made FP more accessible.

\section{Methodology, Data Collection and Analysis}

In my classroom, I used and engaged in action research as my research methodology. Crookes [39] distinguishes between two kinds of action research for L2 contexts, the first which he refers to as "teacher research" (p. 137) and the second which has a more critical orientation. While Crookes asserts that both kinds of action research are important, he explains that the second kind looks to "[address] the immediate needs and problems of teachers ... support the process of teacher reflection ... facilitate teachers doing other kinds of research and using the results of such research ... and [face] up to the unquestioned values embodied in educational institutions ..." (p. 137). It is this kind of critically oriented action research that I sought to engage with in my classroom.

I rely on Burns' [40] definition of action research as "reflective practice and the teacher as researcher [which] involves taking a self-reflective, critical, and systematic approach to exploring your own teaching contexts" (p. 2). According to Burns, there are four steps in the action research process. First, in the planning stage, one identifies the problem and develops a plan to address it. Then, in the action stage, the plan is incorporated into the teaching (i.e., the plan is put into action). Next, the effects of the action are observed. Lastly, in the reflection stage, the effects are documented and then evaluated, and one reflects on the outcome. Through these four stages, action research allows the teacher to use self-reflection to identify problems and develop new ideas and alternatives to aspects of their teaching that they think can be improved or are problematic. This gives the teacher the opportunity to rework, rethink and discover how to address problems in the classroom.

Data collection consisted of collecting all student work and writing assignments, student interviews and the three surveys distributed throughout the semester, as well as my own teaching journal and field notes. Student work was collected throughout the semester as assignments and other activities were handed in or collected in class. The surveys were open-ended or Likert scale questions meant to gauge students' opinions and reactions to teaching materials and content as well as to collect feedback and suggestions about the course. The surveys were distributed electronically and filled out anonymously by the students. The surveys were given to students during week 4 , week 9 and on the final day of class in week 16 . Some questions from each survey were repeated in all the three surveys while others varied, were added or deleted. This was a result of my own reflective processes and desire to question different aspects of the course as the semester progressed.

Just before the end of the semester, I contacted all of my students and asked if they would be willing to participate in a one-on-one in-person interview with me. Six students responded that they would like to be interviewed (three women and three men). All interviews were semi-structured and audio-recorded. The interviews lasted between twenty-five minutes and one hour.

As I was interested to see what themes might emerge across different student interviews, I chose to use inductive coding [41]. I first started by listening to the interviews and transcribing my data. After that, I closely read and listened to the transcriptions several times, remaining open to the "multiple meanings that are inherent in the text" [41] (p. 241). As I interpreted my transcripts, students' critical consciousness and development of their L2 writing emerged as recurrent themes. I then coded my interview data for these themes. Once coded, I closely analyzed the relevant sections containing these themes and added transcription conventions which have been adapted from [42]. Once coding was complete, I triangulated my data by looking for instances where interview themes were supported by student work and survey data. 


\section{Findings}

\subsection{Emergence of Critical Consciousness}

Looking at the data as a whole across interviews, field notes and surveys, the students responded positively to the course. In all the three surveys, the majority of the students indicated that they found the course relaxing and interesting. Only two students stated that they did not enjoy the theme "Culture and Gender" because they were not used to talking about these topics. It is true that engaging in a feminist process enabled the students to participate in topics that they may not have otherwise. In my opinion as the teacher, this process played out well, creating a highly interactive classroom in which the vast majority of students found it stimulating to engage with feminist topics and processes.

While many themes emerged across the dataset, as one of the main goals of FP is fostering a critical and feminist consciousness in students, I focused the first section of my findings on the development of my students' critical consciousness (CC). Watts et al. [43] characterize CC as having three important components. The first is critical reflection, which "refers to a social analysis and moral rejection of societal inequities, such as social, economic, racial/ethnic, and gender inequalities that constrain well-being and human agency" (p. 47). Similar to other scholars such as Diemer et al. [44] and Lundy [8], Watts et al. see reflection that leads to recognition of social inequalities as the first step in developing CC. Once critical reflection has begun and an individual can situate injustice within "systemic terms," they may start developing political efficacy or "the perceived capacity to effect social and political change by individual and/or collective activism" (p. 46). Watts et al. argue that when a person is able to engage in critical reflection and develops political efficacy, they will then hopefully partake in the last stage of CC, critical action. "[Referring] to individual or collective action taken to change aspects of society, such as institutional policies and practices, which are perceived to be unjust" (pp. 46-47), critical action may be characterized as any number of activities or activism meant to enact social change.

Through students' engagement with FLP, both in the curriculum and through the writing process, formation of CC was notable. In both interviews and writing, the students illustrated critical reflection and the emergence of political efficacy. Such was the case in an interview with my student, Ellen (all names used are pseudonyms), who is originally from Asia. I asked Ellen what her feelings and thoughts were towards our class theme "Gender and Culture" and if they had changed throughout the semester. Ellen's response below illustrates how she started to develop her CC through the process of critical reflection.

\section{Excerpt 1:}

1 E: I can use my own perspective to look at this topic and judgment and (.) yeah to

2 understand it more, more than just like it's a female and male problems.

3 H: what do you mean by it's more than just female male?

4 E: because um when I just know about this topic I think it's about discrimination but

5 like (.) when I really write about this topic I need to like look at the social structure

6 and the cultural things and for example the oral tradition and the male culture, how

7 they changed so I think it helped me to look at the big picture and more than just

8 discrimination.

In the above excerpt, we can see how Ellen had begun to develop CC through her ability to make critical reflections. That is, she made a critical, social analysis that illustrates an understanding of how oppression functions. In lines 1-2, Ellen indicates that she sees the problem of gender inequality as more than just a problem of discrimination between men and women. Ellen specifies that in order to understand and examine gender inequality through writing, it was necessary for her to examine and "look at" social structures (5). By doing so, she could no longer attribute gender inequality just to "discrimination" but was forced to reflect on and recognize the role of "social structure" and "cultural things" in inequality (5-8). As Ellen indicates, it is "more than just discrimination" (7-8) and she can now look at the "big picture" (7). Ellen's critical examination of gender discrimination led her to make a critical reflection. This reflective process resulted in a new understanding in which Ellen saw discrimination as entrenched in and enacted through 
social structures that create systemic inequality. As Yu [45] notes, when a person has developed CC, "links between individual difficulties and societal structures are recognized" (p. 7). By critically reflecting on the cause of inequalities through writing and linking them to societal structures, students such as Ellen call attention to oppressive structures and start disrupting them.

When making critical reflections such as Ellen's above, many students started by questioning their own epistemologies in relation to gender norms and dynamics. In excerpt 2, I asked Anna, originally from Europe, to reflect on her reactions and feelings toward our class theme "Gender and Culture." Below, she makes a critical reflection about how her previous experiences shaped her understandings of gender.

\section{Excerpt 2:}

9 H: OK, do you feel like you learned anything from this theme? Took anything new 10 away from it?

11 A: I would say like (.) how big of a problem like gender discrimination is, like still is. 12 People in general often like forget how big of a problem it still is (.) like maybe, also 13 for me like thinking back how many problems or how many things I actually 14 experienced that had to do with gender which I didn't realize before that (.) just like 15 reflecting on my on my past and thinking about that.

$16 \mathrm{H}$ : Do you have an example? Of something maybe that the theme maybe made you 17 think about or an experience?

18 A: Probably like the like the how different my like how different I grew up from a lot 19 of other kids back home my parents raised me with my brothers basically saying you 20 could be whatever you want like you don't have to be like, you don't have to be a

21 specific gender basically which I as a kid didn't realize as much was so different but 22 now realized thinking back on it.

Above, Anna acknowledges that the theme made her aware of how prevalent gender discrimination still is (11). She then makes a critical reflection, noting that many things she experienced in the past were actually linked to gender. While she had not realized this before, the ability to engage with the theme and FLP in the classroom allowed her to reflect on how formative past experiences were related to gender (13-22). This critical reflection is confirmed in Anna's narrative essay in which she passionately and eloquently reflected on how gender affected her childhood. The narrative assignment asked students to reflect on an experience that impacted their understanding of the ways in which culture and gender affect their lives.

In Anna's essay, she reflects on the role gender had in shaping her. Early in her essay, she explains that although she felt different from some of the other girls in her school, she did not care because she had what made her happy above all else: soccer. She was good, eventually playing for a prestigious club which she says "is known for having the best female-soccer team in the world." Unfortunately, Anna was ultimately kicked off the team and eventually forced to stop playing altogether due to an injury. This was a tragic turning point for Anna who writes:

But now, since I was no longer able to play, that talent did not matter anymore and I had nothing to defend myself against society... At lunch, instead of playing soccer, I now sat with the other girls, talking about makeup and celebrities. I did not care about these things at all, but I acted like I did. When I had to go somewhere, I would not run like I used to but rather walk, because "girls don't run" (at least that is what the others said). I stopped wearing soccer clothes during gym class and asked my mom to buy me more girly clothes. After changing all those things, I had more friends again, was from now on only the genius kid. I did not like that change and I felt like I had to give up on myself. Looking back now, I think although I did not abandon my personality, I was forced to learn how to play the character that society wanted me to play and it certainly did not make me happy. 
After all I've been through I can say that, the saying that you can choose your own life, is a lie, society decides it. You can try to change that, but in the end it will cost a lot of energy. I ended up moving to the US where I found friends with whom I did not had to play a character. I was happier in the US than I was in [Europe]. But every time when I go back to [Europe], I have to play that character, and I do it. However, as I get older and wiser (that sounds kind of weird because I'm only [a young undergraduate student]), I can see how I, from day to day, play the character less. How I learn to just be myself again, get my old self back. And I think now that maybe, if society has a problem with who I am, maybe society just needs to change, not me.

Anna's narrative writing shows the emergence and evolution of CC and critical reflection in many ways. First, Anna acknowledges the role society plays in shaping gender expectations. In doing so, she illustrates her understanding of gender expectations as something people are socialized into, something that is constructed and performed like a character in a play. As with Ellen, Anna's recognition of the role of society and social structures in creating oppressive environments and unequal power relations is a crucial critical reflection, demonstrating the emergence of CC. Although Anna critically reflects on and critiques the role she felt society took in forcing her to act and be "the girl society wanted me to be" - exclaiming that to believe you can choose your own life is "a lie" - her essay ends on a cathartic note. At the beginning of the last paragraph, Anna seems to feel helpless against societal expectations but she quickly reasserts her agency. She explains that she has begun rejecting harmful societal expectations since moving to the US, and ends strongly by exclaiming "if society has a problem with who I am, maybe society just needs to change, not me." This last sentence demonstrates the next phase in Anna's CC evolution - political efficacy. Anna accuses society of creating oppressive gender expectations. This accusation allows her to shift the responsibility of upholding oppressive expectations from herself to society, declaring that it is not she who must change, but society. By asserting such agency and shifting the frame of responsibility, political efficacy-or one's perceived ability to create change-is manifested. Anna no longer sees herself as a passive victim but as someone with agency who may enact change. The presence of critical reflection culminating in political efficacy in Anna's writing both demonstrates and confirms the emergence of her CC. In this way, I argue that in the context of this study, FLP acted as an effective consciousness-raising tool in my EAP classroom, aiding in students' CC development.

\subsection{L2 Writing Development}

Engaging students in pedagogy that ultimately leads to critical consciousness raising is a clear goal among feminist pedagogues and scholars. However, while such practices may lead to the development of CC, in the feminist pedagogy language literature, little (if any) attention is paid to L2 development. In the context of this study, I am referring to language as knowledge and application of certain L2 genres, discourse structures and writing strategies. In the past, when I discussed the benefits of feminist pedagogical approaches with other teachers, I was often asked "But do they learn the language?" There seems to be a concern that making room for and focusing on feminist classroom practices means there is less time and space for language development to occur. However, adapting one does not mean losing the other. Students can cultivate critical consciousness and at the same time learn and develop a language. In fact, incorporating feminist practices and topics can even serve as a motivational tool for language development. This is illustrated in excerpt 3 where Samuel—originally from Europe-tells me about his favorite writing assignment, the student-led free writes.

In this assignment, the students were asked to identify a critical issue (in the assignment guidelines, I specified this as a social issue that could be argued from multiple perspectives) and present it briefly to the class. The students presenting were also responsible for creating discussion questions. After a short topic presentation, the students spent 
ten minutes free writing on the topic and the questions. Below, Samuel explains why he thought free writes on critical issues helped improve his overall L2 writing.

\section{Excerpt 3:}

23 H: How did it help you to improve your writing?

24 S: Um just to put my ideas on the spot, with, with the (.) I mean not a great

25 organization at least that's how I approach free writes just put as many ideas as I

26 could on the paper and then ah that's why it helped me a lot to to (1) to start my uh

27 my papers for example the narrative it helped me a lot and the research paper and

28 um so I would put my ideas in order and then when I looked at it I had a good like

29 foundation to start my paper and um (1) so yeah I think the free writes definitely, the 30 ones I the ones that (.) helped me the most in my writing.

$31 \mathrm{H}$ : And what do you think about it being over critical issues do you think that helped 32 your writing?

33 S: (3) I mean, it did, and ah I just find it really interesting to write about critical issue 34 and uh when you write about critical issues I guess you have (.) something to really 35 think about and so uh and something that you that you (.) that's one of your concerns 36 so I guess you (2) um you actually, at least in my case enjoy time when you're writing 37 it you know? Because it uh because you care about that.

Excerpt 3 shows that Samuel developed a brainstorming strategy for writing. When applying this strategy, he first puts as many details down on paper as possible, allowing his ideas to flow uninterrupted before going back and organizing them (25-29). As he says, this gives him a foundation to start his paper (29). Here, Samuel meets the first SLO listed in the syllabus: "[Students will be able to] provide evidence of effective strategies for generating, revising, editing, and proofreading a text in order to produce finished prose." Samuel's articulation of how he benefits from the free writing process demonstrates that he understands these benefits and consciously applies and practices various writing strategies-such as brainstorming, editing, revising and reordering-as a process to work towards generating "finished prose." These were all strategies that we practiced in class as one of my personal goals was to develop the students' writing fluency and brainstorming through free writes.

In addition to demonstrating his language development through his understanding and application of writing strategies, Samuel also states that writing about critical issues helped his writing development. He explains that the issues were things he found interesting, things he cared about, things that made him think, things he enjoyed writing about (33-37). In this way, the critical issues served not just as a writing prompt, but as a motivational writing tool.

In fact, Samuel's interest in and belief that critical issues are important was shared among the majority of his classmates. In Tables 2 and 3, one question asked "Do you think it is important to talk about critical issues in class? (Such as politics, the environment, race, gender, etc.) Why or Why not?" The students' responses are illustrated in Tables 2 and 3 below.

Table 2. Survey 2.

\begin{tabular}{cc}
\hline $\begin{array}{l}\text { Do You Think It Is Important to Talk about Critical Issues in } \\
\text { Class? (Such as Politics, the Environment, Race, Gender, etc.) }\end{array}$ & Number of Students \\
\hline Yes & 9 \\
\hline It depends & 1 \\
\hline Not yes or no & 0 \\
\hline No & 2 \\
\hline Did not respond to the survey & 2 \\
\hline
\end{tabular}


Table 3. Survey 3.

\begin{tabular}{cc}
\hline $\begin{array}{c}\text { Do You Think It Is Important to Talk about Critical Issues in } \\
\text { Class? (Such as Politics, the Environment, Race, Gender, etc.) }\end{array}$ & Number of Students \\
\hline Yes & 10 \\
\hline It depends & 0 \\
\hline Not yes or no & 1 \\
\hline No & 1 \\
\hline Did not respond to the survey & 2 \\
\hline
\end{tabular}

The surveys also asked the students to elaborate on their responses and explain why they did or did not believe it was important to talk about critical issues in class. Like Samuel, many of the students explained that they found the issues not only interesting but were things they cared about, enjoyed discussing and relevant to their lives. For example, one student wrote: "It is important to talk about critical issues in class ... because we have classmates from many different countries, so it is a good chance for all of us to know and understand different views of looking at the world." Another said: "These critical issues are essential to us." From the students' responses, it is clear that they enjoyed writing about critical issues and found them interesting and motivating to engage with.

In addition to asking about critical issues, survey 3 also asked students if they felt their writing had improved over the semester. As seen in Table 4, all the students who responded to the survey answered "yes."

Table 4. Student reflection on writing.

\begin{tabular}{cc}
\hline Do You Feel Your Writing Has Improved over the Semester? & Number of Students \\
\hline Yes & 12 \\
\hline No & 0 \\
\hline Did not respond to the survey & 2 \\
\hline
\end{tabular}

Although the above data are self-reported, when asked how they felt their writing had improved, many students cited knowledge and examples of different writing skills, various writing strategies, knowledge of different genres and knowledge of discourse structures as evidence of their improved L2 writing. As the instructor, I can also attest that the students' writing and language progressed throughout the semester. What is important, however, is not so much that the students' language developed-as might be expected in an EAP classroom - but that it developed alongside their critical consciousness. From the above data, we see that FLP served not only to foster consciousness-raising, but also as a motivational language learning tool. The students found it important to work with critical feminist issues and enjoyed engaging with these issues while using the target language and developing their writing.

\section{Discussion}

It is important to consider that when implementing feminist or other liberatory pedagogies, educators usually must work around and within various constraints and administrative pressures $[31,46,47]$. However, due to my teaching environment, I was able to focus entirely on my students' development and the implementation of FLP in the classroom. While I had ample freedom and support, I still wondered (and admittedly worried) if sixteen weeks would be long enough to cultivate CC through FLP while also focusing on L2 writing composition. Ultimately, as the data and findings presented here indicate, it was.

In fact, I argue that my analysis and data confirm the consciousness-raising power of FLP in a second language learning context. The students' emerging CC was evident in their 
course work and conversations with me. Through their writing and the course theme, they started critiquing and considering the role of societal structures in perpetuating gender inequality. These critical reflections at times led the students to form political efficacy, no longer seeing themselves as passive agents, but as reactive citizens with the ability to enact change and challenge oppression. FLP served as the consciousness-raising tool, aiding students in cultivating their CC.

While the students demonstrated the first two steps noted by Watts et al. [43] in fostering CC (critical reflection and political efficacy), there is no evidence that they demonstrated the third step, critical action. While there is some literature that illustrates what it looks like when students take critical action [48,49], this seems to be an area that is both difficult to demonstrate and hard to accomplish over a short period of time. From my own personal reflections and experience, I believe that students need heavy scaffolding and support when taking critical action, time to develop CC, trust and comfort with the instructor and their classmates and time to take steps towards taking action (note that both Cowhey's and Ferguson's courses took place over a full, or more than one, academic year). It may be that expecting students to take critical action over a short period of time is asking too much. However, this study demonstrates that while we may not see critical action take place, it is possible to support students' CC development in an FLP classroom over a relatively short period of time. This, of course, is the first step that must be achieved if we hope for our students to become active citizens. Regardless, we need more studies that examine the consciousness-raising power of FLP and its potential to lead students towards critical action.

While FLP aided the students' CC development, it also served as an effective motivational language learning tool. The students enjoyed participating in an FLP classroom and topics. This ultimately motivated them to engage with the language and develop their L2 writing, specifically in the areas of genre, discourse structures and writing strategies. This illustrates that language learning does not need to be sacrificed for liberatory classroom practices but may happen in conjunction with them. I thus urge future researchers and teachers who would like to implement FLP in their classrooms to document and report their students' language learning. Documenting language growth is important in order to show students their improvement, but can also be a means of justifying feminist and critical pedagogies to administrators. While the students in my class may have learned the same writing skills and achieved the SLOs implemented by the administration in a conventional classroom, in my feminist classroom, they were able to do so while also developing critical consciousness. If teachers can show that by using FLP they are not sacrificing language learning but motivating and nurturing it while practicing liberatory and innovative pedagogies, it may be possible to confront some of Sattler's [31], Crabtree and Sapp's [46] and Webber's [47] concerns of unsupportive or hostile administrations and teaching environments.

\section{Conclusions}

As the iconic feminist theorist Donna Haraway said in a 2014 address, "It matters what stories tell stories. It matters what thoughts think thoughts. It matters what worlds world worlds" [50] (5:50). If we want our students to tell stories, think critically, analyze oppressive world-making and take action to address it, we must make FP and other liberatory teaching practices a priority in our classrooms. Specifically, we must address those areas where examples of such practices are scarce, such as in second language learning contexts. If we want to see change in our students, in our current situations and in our world, we must create the safe space and time necessary to allow students to develop their own agency, power and knowledge. I believe FP is one way of doing this and of addressing the complexities of our modern world. I hope that this paper serves to help other educators imagine the ways in which they may implement such practices in their own classroom. I hope it helps them see the emergent possibilities of such a pedagogy as 
well as the many directions and concerns we must continue to address and explore together with the hope of taking small steps towards making new, more equal, responsible worlds.

Funding: This research received no external funding.

Institutional Review Board Statement: The study was conducted according to the guidelines of the Declaration of Helsinki, and approved by the Institutional Review Board (or Ethics Committee) of The University of Hawaii at Mānoa (protocol code 2018-01110, 16 January 2019).

Informed Consent Statement: Informed consent was obtained from all subjects involved in the study.

Data Availability Statement: The data presented in this study are available on request from the corresponding author. The data are not publicly available due to privacy.

Conflicts of Interest: The author declares no conflict of interest.

\section{References}

1. Schniedewind, N. Teaching feminist process in the 1990s. Women's Stud. Q. 1993, 21, 17-30.

2. Crookes, G. Critical ELT in Action: Foundations, Promises, Praxis; Routledge: New York, NY, USA, 2013.

3. Weiler, K. Freire and a feminist pedagogy of difference. Harvard Educ. Rev. 1991, 61, 449-475. [CrossRef]

4. Jaggar, A. Love and knowledge: Emotion in feminist epistemology. Inquiry 1989, 32, 151-176. [CrossRef]

5. Grande, S. Whitestream Feminism and the colonialist project: A review of contemporary feminist pedagogy and praxis. Educ. Theory 2003, 53, 329-346. [CrossRef]

6. Ferguson, K. Feminist theory today. Ann. Rev. Political Sci. 2017, 20, 269-286. [CrossRef]

7. Ochoa, A.; Pershing, L. Team teaching with undergraduate students: Feminist pedagogy in a peer education project. Fem. Teach. 2011, 22, 23-42. [CrossRef]

8. Lundy, C. Social Work, Social Justice, and Human Rights; University of Toronto Press: Toronto, ON, Canada, 2011.

9. Klatch, R. The formation of feminist consciousness among left- and right-wing activists of the 1960S. Gend. Soc. 2001, 15, 791-815. [CrossRef]

10. Reimer, G. Female consciousness: An interpretation of interviews with Inuit women. Études/Inuit/Studies 1996, $20,77-100$.

11. Hooks, B. Talking Back: Thinking Feminist, Thinking Black; South End Press: Boston, MA, USA, 1989.

12. Shrewsbury, C. What is feminist pedagogy? Women's Stud. Q. 1997, 25, 166-173.

13. Boler, M. Feeling Power; Taylor \& Francis: Hoboken, NJ, USA, 1999.

14. Delgado, A. Defying cultural norms: Launching women's studies in the high school setting. In Feminist Pedagogy, Practice and Activism: Improving Lives for Girls and Women; Martin, J.L., Nickels, A.E., Sharp-Grier, M., Eds.; Routledge: New York, NY, USA, 2017; pp. 85-103.

15. Dorney, J.A. Teaching a course on women and anger: Learning from college students about silencing and speaking. In Feminist Pedagogy in Higher Education: Critical Theory and Practice; Penny, T.L., Nicholas, J., Bondy, R., Eds.; Wilfrid Laurier UP: Waterloo, ON, USA, 2015; pp. 85-103.

16. Gullage, A. Fat lessons: Fatness, bodies, and the politics of feminist classroom practice. In Feminist Pedagogy in Higher Education: Critical Theory and Practice; Penny, T.L., Nicholas, J., Bondy, R., Eds.; Wilfrid Laurier UP: Waterloo, ON, USA, 2015 ; pp. 113-125.

17. Martin, G.L. And the danger went away: Speculative pedagogy in the myth of the post-feminist. In Feminist Pedagogy, Practice and Activism: Improving Lives for Girls and Women; Martin, J.L., Nickels, A.E., Grier, M.S., Eds.; Routledge: New York, NY, USA, 2017; pp. 5-34.

18. Lakoff, R. Language and woman's place. Lang. Soc. 1973, 2, 45-79. [CrossRef]

19. Tannen, D. You Just don't Understand: Women and Men in Conversation, 1st ed.; Morrow: New York, NY, USA, 1990.

20. Tannen, D. Gender and Conversational Interaction; (Oxford Studies in Sociolinguistics); Oxford University Press: New York, NY, USA, 1993.

21. Tannen, D. Gender and Discourse; Oxford University Press: New York, NY, USA, 1994.

22. Pavlenko, A. Bilingualisn, Gender, and Ideology. Int. J. Biling. 2001, 5, 117-151. [CrossRef]

23. Pavlenko, A.; Blackledge, A.; Piller, I.; Teutsch-Dwyer, M. (Eds.) Multilingualism, Second Language Learning, and Gender; Mouton de Gruyter: Berlin, Germany; New York, NY, USA, 2001.

24. Pavlenko, A.; Piller, I. Language education and gender. In Encyclopedia of Language and Education; May, S., Ed.; Springer: Berlin/Heidelberg, Germany, 2007; Volume 1, pp. 57-69.

25. Piller, I.; Pavlenko, A. Bilingualism and gender. In Handbook of Bilingualism; Bhatia, T., Ritchie, W., Eds.; Blackwell: Oxford, UK, 2004; pp. 489-511.

26. Vandrick, S. Feminist pedagogy and ESL. Coll. ESL 1994, 4, 69-92.

27. Vandrick, S. Promoting gender equity in the postsecondary ESL class. In Adult ESL: Politics, Pedagogy, and Participation in Classroom and Community Programs; Smoke, T., Ed.; Erlbaum: Mahwah, NJ, USA, 1998; pp. 73-88.

28. Vandrick, S. Feminist pedagogies in global TESOL communities. In Proceedings of the Panel Discussion Presented at 2005 TESOL Conference, San Antonio, TX, USA, 7-11 March 2005. 
29. McMahill, C. Self-expression, gender, and community: A Japanese feminist English class. In Multilingualism, Second Language Learning, and Gender; Pavlenko, A., Blackledge, A., Piller, I., Teutsch-Dwyer, M., Eds.; Mouton: Berlin, Germany, 2001 ; pp. 307-344.

30. Petrie, B.M. ESL through issues in the women's movement. TESL Can. J. 1985, 3, 59-69. [CrossRef]

31. Sattler, C.L. Talking about a Revolution: The Politics and Practice of Feminist Teaching; Hampton Press: Cresskill, NJ, USA, 1997.

32. Schenke, A. Not just a "social issue": Teaching feminist in ESL. TESOL Q. 1996, 30, 155-159. [CrossRef]

33. McMahill, C.; Reekie, K. Forging alliances: Grassroots feminist language education in the Tokyo area. In Gender Issues in Language Education; Casanave, C., Yamashiro, A.D., Eds.; Keio University SFC: Fujisawa, Japan, 1996; pp. 15-30.

34. Smith, S.; Yamashiro, A. Gender issues in language teaching. Spec. Issue Lang. Teach. 1998, 22, 1-2.

35. Cheira, A. (Fostering) princesses that can stand on their own two feet: Using wonder tale narratives to change teenage gendered stereotypes in Portuguese EFL classrooms. In Teaching Gender: Feminist Pedagogy and Responsibility in Times of Political Crisis; Benavente, B.R., Gonzalez, A.M., Eds.; Routledge: New York, NY, USA, 2017; pp. 146-162.

36. Yoshihara, R. The Socially Responsible Feminist EFL Classroom: A Japanese Perspective on Identities, Beliefs and Practices; Multilingual Matters: Bristol, UK, 2017.

37. Martin, J.L.; Nickels, A.E.; Sharp-Grier, M. (Eds.) Feminist Pedagogy, Practice, and Activism: Improving Lives for Girls and Women; Routledge: New York, NY, USA, 2017.

38. Mccusker, G. A feminist teacher's account of her attempts to achieve the goals of feminist pedagogy. Gend. Educ. 2017, 29, 445-460. [CrossRef]

39. Crookes, G. Action research for second language teachers: Going beyond teacher research. Appl. Linguist. 1993, 14, 130-144. [CrossRef]

40. Burns, A. Doing Action Research in English Language Teaching: A Guide for Practitioners; Routledge: New York, NY, USA, 2010.

41. Thomas, D.R. A general inductive approach for analyzing qualitative evaluation data. Am. J. Eval. 2006, 27, 237-246. [CrossRef]

42. Atkinson, J.; Heritage, J. Structures of Social Action: Studies in Conversation Analysis; Cambridge University Press: Cambridge, UK, 1984.

43. Watts, R.J.; Diemer, M.A.; Voight, A.M. Critical consciousness: Current status and future directions. In Youth Civic Development: Work at the Cutting Edge; Flanagan, C.A., Christens, B.D., Eds.; Wiley: Hoboken, NJ, USA, 2011; Volume 134, pp. 43-57. [CrossRef]

44. Diemer, M.; Rapa, L.; Park, C.; Perry, J. Development and validation of the critical consciousness scale. Youth Soc. 2017, 49, 461-483. [CrossRef]

45. Yu, N. Consciousness-raising and critical practice. In Consciousness-Raising: Critical Pedagogy and Practice for Social Change; Yu, N., Ed.; Routledge: New York, NY, USA, 2018; pp. 1-14.

46. Crabtree, R.; Sapp, D. Theoretical, political, and pedagogical challenges in the feminist classroom: Our struggles to walk the walk. Coll. Teach. 2003, 51, 131-140. [CrossRef]

47. Webber, M. Transgressive pedagogies? Exploring the difficult realities of enacting feminist pedagogies in undergraduate classrooms in a Canadian university. Stud. High. Educ. 2006, 31, 453-467. [CrossRef]

48. Cowhey, M. Black Ants and Buddhists: Thinking Critically and Teaching Differently in the Primary Grades; Stenhouse: Portland, ME, USA, 2006.

49. Ferguson, P. The politics of adult ESL literacy: Becoming politically visible. In Adult ESL: Politics, Pedagogy, and Participation in Classroom and Community Program; Smoke, T., Ed.; Lawrence Erlbaum: Mahwah, NJ, USA, 1998; pp. 3-17.

50. Studio Olafur Eliasson. Anthropocene, Captialocene, Plantationocene, Chthulucene: Staying with the Trouble [Video File]. 9 May 2014. Available online: https:/ / vimeo.com/200992946 (accessed on 20 November 2019). 